\title{
Discussion: Geotechnical properties of a natural zeolite
}

Vasiliki N. Georgiannou MSC, DIC, PhD University of Athens, Athens, Greece

Demetrios Lefas MEng (Cantab)

PhD candidate, University of Cambridge, Cambridge, UK

Maria Konstadinou PhD

Advisor/Researcher, Deltares, Delft, the Netherlands
Associate Professor, School of Civil Engineering, National Technical

Maria Perraki PhD

Assistant Professor, School of Mining and Metallurgical Engineering, National Technical University of Athens, Athens, Greece

Felipe A. Villalobos CEng, MSc, DPhil

Assistant Professor, Catholic University of Concepción, Concepción, Chile (Orcid:0000-0002-5419-3958)

\section{Contribution by F. A. Villalobos}

The work presented by Georgiannou et al. (2017) on geotechnical properties of a natural zeolite is an important contribution because there are not many published works on this subject. The authors mention some of the several studies with natural zeolites in other research areas, mainly in environmental applications such as waste-water treatments, soil-bentonite mixtures and in the improvement of cement and concrete properties. They also mention the existence of numerous engineering and industrial applications of natural zeolites in farming, fisheries, textiles and construction materials. This discussion will complement and comment on some of the results obtained by the authors and suggest that extra information would be useful in order to make a more comprehensive analysis.

The authors point out that clinoptilolite is the mean mineral component of the zeolite, representing at least $85 \%$ of the samples studied. Although it is indicated that clinoptilolite can be found in northern Greece and some islands of the Aegean Sea, it is not pointed out where exactly the samples were extracted and what is the geological context of the zeolite formation.

The specific gravity $G_{\mathrm{s}}$ of the zeolite is $2 \cdot 17$, which is a low value compared with that of typical soils. However, values of $G_{\mathrm{s}}=2.18$ and 2.19 have also been reported in natural zeolites in Chile by Villalobos et al. (2018) and in Turkey by Canpolat et al. (2004), respectively. From this $G_{\mathrm{s}}$ and maximum and minimum void ratio values, the dry unit weight of the samples tested ranges between 9.7 and $12.5 \mathrm{kN} / \mathrm{m}^{3}$. How can these low values be useful or not useful in soil liner and other applications?

The authors carried out oedometer and direct shear tests on two different grain size distributions of ground, prepared samples of natural zeolite. The first zeolite has a wider gradation or is well graded, with particle size varying from 0.01 to $5 \mathrm{~mm}$, with around $25 \%$ silt, $45 \%$ sand and $30 \%$ fine gravel. The second zeolite tested has a more uniform gradation, with particle sizes between 0.075 to $5 \mathrm{~mm}$, with around $58 \%$ sand and $42 \%$ fine gravel. Values for the coefficient of uniformity and curvature are not presented and neither is the plasticity index of the silt component of the first zeolite; therefore, Unified Soil Classification System (USCS) classifications for these zeolites cannot be determined, but they can be described as a silty sand and a clean sand without fines, respectively.

The oedometer tests were interestingly aimed at assessing particle crushing. It was found that particle breakage occurred for vertical stresses higher than $1 \mathrm{MPa}$, resulting in an extra $5 \%$ fines only for the clean sand type zeolite. However, no information was provided on zeolite compressibility in loading-unloading-reloading in terms of $\lambda, \kappa$ or compression and swelling indices $C_{\mathrm{c}}, C_{\mathrm{s}}$ or in terms of constrained modulus to be able to evaluate settlements, for instance, or the coefficient of permeability, which can also be determined in oedometer tests.

The authors showed direct shear test results performed with a circular shear box of $59.8 \mathrm{~mm}$ with normal stresses up to $300 \mathrm{kPa}$. Tests were carried out in two zeolite samples and two uniform sand samples, namely a medium washed sand and Ottawa sand. They analysed the results in terms of peak and ultimate angle of friction and concluded that high values of the angles of frictions were obtained. The first comment is on the size of the shear box. O'Rourke (2010) compared direct shear test results for square shear boxes of 60,100 and $300 \mathrm{~mm}$ side length for angular and sub-angular glacial and fluvial sand deposits around New York, USA. He found that shear boxes smaller than $100 \mathrm{~mm}$ tend to overestimate the maximum or peak dilatation angle $\Psi_{\max }$ and hence the maximum angle of friction $\phi_{\max }^{\prime}$, between 3 and $7^{\circ}$ for the former and between 4 and $6^{\circ}$ for the latter. This could perhaps explain the high values of angles of friction for zeolite.

The second comment is related to the vertical displacements, which were highly likely to have been measured during the tests. The lack of the vertical displacement results does not allow the analysis in terms of contraction and dilation. In plots of vertical against horizontal displacements, the contraction and dilation response can be identified, as well as the rate of vertical to horizontal displacement. The maximum angle of dilation can be determined when the maximum 
positive rate of vertical to horizontal displacement is reached. A constant rate or zero variation can be related to a steady state of vertical displacement. The maximum angle of dilation can be correlated to the maximum angle of friction and the critical state angle of friction as proposed by Bolton (1986). In this form, it would be possible to compare the zeolite and sand results with the relationship proposed by Bolton (1986) for granular soils as it was presented for a Chilean zeolite by Villalobos et al. (2018). This could be another way to conclude whether or not zeolites behave as siliceous sands.

\section{Author's reply}

The dilatancy of sands due to their particulate nature first described by Reynolds (1886) and subsequently expressed by Taylor's stress-dilatancy theory (Taylor, 1948) is a well-known fact. The simple and fundamental direct shear test offers insight into the frictional, confining-stress-dependent mechanism that controls sand's stiffness and strength. In the paper the ratio of mobilised shear stress over the constant normal effective stress defines the mobilised friction angle, $\phi_{\mathrm{mob}}$.

$$
\tan \phi_{\mathrm{mob}}=\frac{\tau}{\sigma_{\mathrm{v}}^{\prime}}
$$

Failure of sand occurs when the stress ratio reaches its maximum value. Consequently, it can be stated that regarding failure the sand is a stress-ratio-dependent material. The mobilised stress ratio plays an important role in all aspects of the mechanical behaviour of sand.
In the paper, the authors did not present the stress-dilatancy relationships in order to reduce the length of the paper; however, the authors concentrated on the mobilised stress ratio, indicating the peak values (mobilised at maximum dilatancy for the dense sands) and the values at the ultimate state of sand. As reported by Casagrande (1936) at ultimate state the sand continues to accumulate shear deformation under constant volume and constant stress ratio. The mobilised stress ratios at peak and ultimate state are directly compared for two sands and two gradations of the zeolite at both the loose and dense state to indicate coherent behaviour.

Following the stress-dilatancy theory proposed by Taylor (1948), at the ultimate state the sand dissipates energy as if it is a purely frictional Coulomb material, which deforms at constant volume with a constant friction angle, as observed by Casagrande (1936). The sand dilatancy defined as the ratio of the relative displacements of the shear-zone boundaries in the vertical and horizontal directions under direct shear loading, $D=d_{y} / d_{x}$, depends on the difference of the current stress ratio, $\eta=\tau / \sigma_{\mathrm{v}}^{\prime}$, from the reference stress ratio at ultimate state, as suggested by Rowe (1962), Schofield and Wroth (1968) and Roscoe and Burland (1968). Peak stress ratio and maximum dilatancy occur simultaneously in dense sand. The corresponding dilatancy plots for sand and zeolite are included in this discussion in Figure 16; the similarity of the plots is apparent, further illustrating the importance of the particulate nature of the zeolite.

Regarding the comment about the sizes of the boxes, although valid in principle, it is stressed that in the present study sands

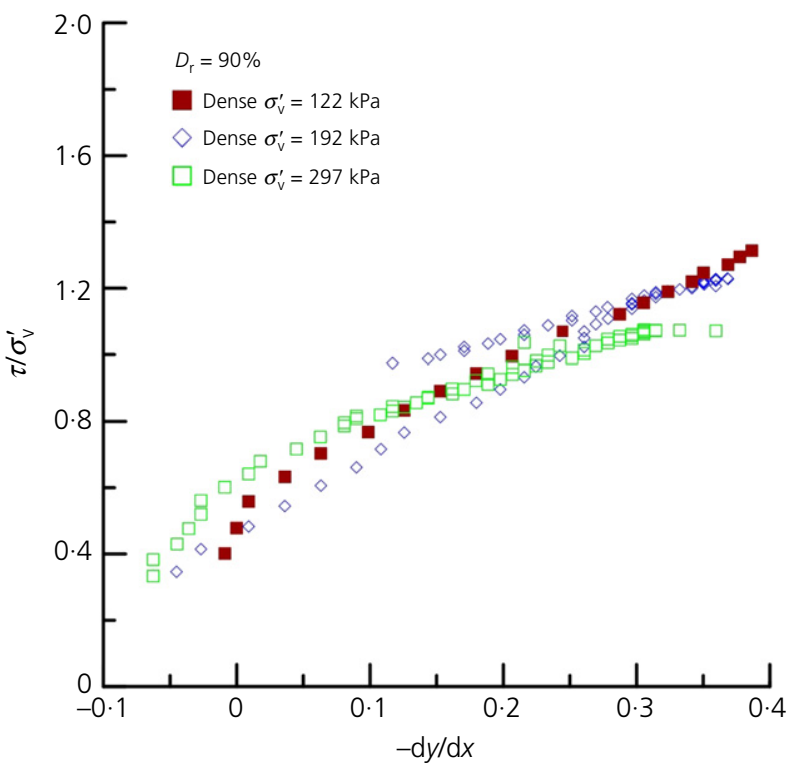

(b)

Figure 16. Stress-dilatancy curves for: (a) zeolite; (b) medium washed sand with similar grading 
and zeolite of similar gradations are tested in the same box; hence direct comparison of results can be made.

The exact location of the zeolite cannot be disclosed because it is proprietary company/sponsor information.

The other bits of information, for example, uniformity coefficient, or compression and swelling indices, can easily be calculated from the relative graphs. Since the zeolite was crushed and ground the material is non-plastic whether in sand- or silt-sized particles. Finally, permeability is expected to have a typical sand value.

The authors reiterate that the main thrust of the paper is on the mechanical behaviour of zeolites, which in turn can be described within the framework developed for sands.

\section{REFERENCES}

Bolton MD (1986) The strength and dilatancy of sands. Géotechnique 36(1): 65-78, https://doi.org/10.1680/geot.1986.36.1.65.

Canpolat F, Yılmaz K, Köse MM, Sümer M and Yurdusev MA (2004)

Use of zeolite, coal bottom ash and fly ash as replacement

materials in cement production. Cement and Concrete Research 34(5): 731-735.
Casagrande A (1936) Characteristics of cohesionless soils affecting the stability of slopes and earthfills. Journal of the Boston Society of Civil Engineering 23: 13-32.

Georgiannou VN, Lefas D, Konstadinou M and Perraki M (2017) Geotechnical properties of a natural zeolite. Proceedings of the Institution of Civil Engineers - Geotechnical Engineering 170(5): 395-406, https://doi.org/10.1680/jgeen.16.00157.

O'Rourke TD (2010) Geohazards and large, geographically distributed systems. Géotechnique 60(7): 505-543, https://doi.org/10.1680/ geot.2010.60.7.505.

Reynolds O (1886) Experiments showing dilatancy, a property of granular material, possibly connected with gravitation. Proceedings of the Royal Institution of Great Britain 11: 354-363.

Roscoe KH and Burland JB (1968) On the generalized stress-strain behaviour of 'wet' clay. In Engineering Plasticity (Heyman J and Leckie FA (eds)). Cambridge University Press, Cambridge, UK, pp. 535-609.

Rowe PW (1962) The stress-dilatancy relation for static equilibrium of an assembly of particles in contact. Proceedings of the Royal Society of London A 269(1339): 500-527.

Schofield AN and Wroth CP (1968) Critical State Soil Mechanics. McGraw-Hill, London, UK.

Taylor DW (1948) Fundamentals of Soil Mechanics. Wiley, Hoboken, NJ, USA.

Villalobos FA, Leiva EA, Jerez OA and Poblete ME (2018) Experimental study of the effect of fine particles on the shear strength of tuff zeolites. Revista de la Construcción 17(1): 23-37. 